\title{
Avaliação de prebióticos como promotor de crescimento para suínos nas fases de recria e terminação
}

\author{
Evaluation of prebiotics as growth promoters to swine on \\ growing and finishing phases
}

\author{
Juliana Contrera Bellé ${ }^{1}$; Caio Abércio da Silva ${ }^{2 *}$; \\ Ana Maria Bridi²; Graziela Drociunas Pacheco ${ }^{1}$
}

\begin{abstract}
Resumo
O experimento foi conduzido com o objetivo de avaliar os efeitos de um promotor de crescimento à base de prebióticos em rações de suínos em fase de crescimento e terminação sobre o desempenho, características de carcaça e a qualidade de carne. Quarenta e oito suínos machos castrados, de mesma genética comercial, foram alojados com peso inicial médio de $32,48 \pm 3,71 \mathrm{~kg}$ e 72 dias de idade até o abate, realizado aos $115,89 \pm 7,42 \mathrm{~kg}$ e 156 dias de idade. O delineamento experimental foi em blocos ao acaso, com 4 tratamentos e 6 repetições, sendo cada baia com dois animais considerada uma unidade experimental. Para as análises de carcaça e de qualidade da carne foi utilizado o delineamento inteiramente ao acaso, sendo que cada animal representou uma repetição. Foram definidos, através da inclusão dos microingredientes às rações, os seguintes tratamentos: T1-controle (ração isenta de promotor de crescimento); T2- 0,2\% prebióticos $(0,1 \%$ mananoligossacarídeo $+0,1 \%$ frutoligossacarídeo); T315 ppm apramicina; T4- 0,2\% prebióticos $(0,1 \%$ mananoligossacarídeo $+0,1 \%$ frutoligossacarídeo $)+$ $15 \mathrm{ppm}$ de apramicina. O desempenho dos animais foi analisado nas Fases I (entre 30 e $50 \mathrm{~kg}$ de peso vivo), II (entre 30 e $80 \mathrm{~kg}$ de peso vivo) e total (entre $30 \mathrm{~kg}$ e o abate). Não foram verificadas diferenças para as variáveis de desempenho no período total do experimento $(\mathrm{P}>0,05)$. A característica área de olho de lombo dos animais tratados com o prebióticos foi maior $(\mathrm{P}<0,05)$ em relação ao tratamento controle. Não foram verificadas diferenças entre os tratamentos para as características sensoriais e de qualidade da carne $(\mathrm{P}>0,05)$. $\mathrm{O}$ uso de prebióticos para suínos em fase de crescimento e terminação, em relação à apramicina, demonstrou resultados semelhantes no desempenho e nascaracterísticas de carcaça e carne.
\end{abstract}

Palavras-chave: Aditivo, desempenho, carcaça, qualidade de carne

\begin{abstract}
This experiment was conducted with the aim to evaluate the prebiotics as growth promoter in the rations to growing and finishing pigs over the performance, carcass and meat quality characteristics. Forty-eight castrated male pigs with the same genetic background were evaluated. The animals were allocated with $32.48 \pm 3.71 \mathrm{~kg}$ of body weight with 72 days of age, been slaughtered with $115.89 \pm 7.42 \mathrm{~kg}$ with 156 days of age. The experimental design was a randomized blocks with four treatments, six repetitions, been each pen, with two animals, considered one experimental unit. To the carcass and meat evaluation the experimental design was completely randomized, been each animal considered one repetition. According to the rations additives, the following treatments were established: T1- control (ration without growth
\end{abstract}

\footnotetext{
Alunos do Curso de Pós-graduação em Ciência Animal da Universidade Estadual de Londrina.

2 Docentes. Universidade Estadual de Londrina. Departamento de Zootecnia. Campus Universitário. Caixa Postal 6001. CEP 86051-970. Telefone: 43 33714475. Email: casilva@uel.br

* Autor para correspondência
} 
promoter); T2- $0.2 \%$ prebiotics $(0.1 \%$ mannanoligosaccharide $+0.1 \%$ fructooligosaccharide); T3apramicine $15 \mathrm{ppm}$; T4- $0.2 \%$ prebiotics $(0.1 \%$ mannanoligosaccharide $+0.1 \%$ fructooligosaccharide $)$ + apramicine $15 \mathrm{ppm}$. The animals' performance was analyzed considering the Phase I (between 30 to $50 \mathrm{~kg}$ of body weight), II (between 30 to $80 \mathrm{~kg}$ of body weight) and Total (between 30 to the slaughter). There were no differences $(\mathrm{P}>0.05)$ between the treatments to the performance parameters considering the Total phase. The loin eye area characteristic was better $(\mathrm{P}<0.05)$ to the animals treated with prebiotics compared to the control treatment. No differences were observed between the treatments to the meat quality and sensorial characteristics $(\mathrm{P}<0.05)$. The use of prebiotics to growing and finishing pigs demonstrated similar results on the performance, carcass and meat characteristics compared with apramicine treatment.

Key words: Additive, carcass, meat quality, performance

\section{Introdução}

Os antimicrobianos promotores de crescimento têm sido regularmente utilizados nas rações de suínos desde a década de 50 . Estes produtos agem na modulação da microbiota intestinal, determinando efeitos diretos e indiretos nos animais, melhorando substancialmente o ganho de peso e a eficiência alimentar (PATTERSON, 2005). Segundo Bellaver (2000), para suínos, o uso de antimicrobianos promotores é capaz de incrementar o ganho diário de peso em torno de $21 \%$ nas fases iniciais e de $10 \%$ na fase de crescimento, comparados com rações isentas destes.

Porém, com o banimento dos antibióticos promotores de crescimento na União Européia, outros produtos alternativos e naturais surgiram no mercado. Estes novos compostos, hoje utilizados em muitos países, devem apresentar elevada eficiência, baixo custo e atender as exigências do consumidor, preservando a ausência de resíduos na carne, o bem estar dos animais e danos ao meio ambiente (CLOSE, 2000).

Estes novos promotores, portanto, devem garantir adequado equilíbrio da microbiota, refletindo positivamente no estado de saúde geral do animal, com influências conseqüentes no desempenho, na qualidade de carcaça e na carne (SILVA; NÖRBERG, 2003).

Os prebióticos, principalmente os frutoligossacarídeos e os mananoligossacarídeos, (FLICKINGER; FAHEY JÚNIOR, 2002) e os extratos vegetais (CUNHA JÚNIOR; SCHEUERMANN, 2005) representam alguns dos promotores alternativos mais estudados, mas que ainda demonstram resultados práticos bastante variados. Muitos fatores, como a composição da microbiota dos animais (MENTEN, 2001) e o tipo de obtenção e preparação destes aditivos (CUMMINGS; MACFARLANE, 2002) podem contribuir para esta diversidade nos resultados.

Com maior freqüência, os leitões lactentes e os leitões desmamados são objeto de avaliações e usuários de programas que adotam os promotores de crescimento alternativos nas dietas, uma vez que, contrário aos animais que estão em fase de crescimento, estes têm uma população microbiana menos estável e definida (GÓMEZ, 2006). Neste sentido, pesquisas com promotores alternativos com suínos em fase de crescimento e terminação são mais escassas (CAMPBELL et al., 2006).

Assim, o objetivo deste trabalho foi avaliar os efeitos do uso de prebióticos como promotores de crescimento nas rações de suínos nas fases de crescimento e terminação sobre o desempenho, as características de carcaça e a qualidade de carne.

\section{Material e Métodos}

O experimento foi conduzido no setor de suinocultura da Universidade Estadual de Londrina, Estado do Paraná. As análises referentes às características de carcaça foram realizadas em um frigorífico localizado a $45 \mathrm{~km}$ de Londrina; e as 
relacionadas à qualidade de carne, no Laboratório de Nutrição Animal do Departamento de Zootecnia e no Laboratório de Análise de Alimentos do Departamento de Ciência e Tecnologia de Alimentos da Universidade Estadual de Londrina.

As instalações experimentais consistiram de 24 baias, de $3 \mathrm{~m}^{2}$ de área $(1,8 \times 1,7 \mathrm{~m})$, edificadas em alvernaria, com piso compacto, equipadas com comedouros metálicos semi-automáticos e bebedouros tipo nipple.

Foram utilizados 48 suínos machos castrados, da genética DB-DanBred, com peso inicial médio de 32,48 $\pm 3,71 \mathrm{~kg}$ e idade de 72 dias, alojados em número de dois animais por baia. $\mathrm{O}$ delineamento experimental foi inteiramente casualizado com restrição na casualização para seis classes de peso inicial, definindo 4 tratamentos e 6 repetições, sendo cada baia considerada uma unidade experimental.

Os tratamentos experimentais consistiram da combinação de $0,2 \%$ de um promotor de crescimento alternativo (Vitalsantos ${ }^{\circledR}$-Techna) composto de prebióticos $(0,1 \%$ mananoligossacarídeo e $0,1 \%$ frutoligossacarídeo) e do antibiótico apramicina, adicionados às rações das fases de crescimento I, II e terminação, sendo:

$\mathrm{T} 1$ = controle (ração isenta de promotor de crescimento);

$\mathrm{T} 2=0,2 \%$ deprebióticos $(0,1 \%$ mananoligossacarídeo e $0,1 \%$ frutoligossacarídeo)

$\mathrm{T} 3=15$ ppm de apramicina;

T4 $=0,2 \%$ deprebióticos $(0,1 \%$ mananoligossacarídeo e $0,1 \%$ frutoligossacarídeo) $+15 \mathrm{ppm}$ de apramicina

As rações utilizadas nos tratamentos foram fornecidas à vontade e possuíam os mesmos valores nutricionais, sendo formuladas visando atender as exigências mínimas recomendadas pelo National Research Council - NRC (1998). Foram utilizadas rações específicas para as fases de Crescimento I (30 aos $50 \mathrm{~kg}$ de peso vivo), Crescimento II (50 aos $80 \mathrm{~kg}$ de peso vivo) e Terminação $(80 \mathrm{~kg}$ até o peso de abate). A composição percentual e centesimal das rações basais encontra-se na Tabela 1 .

Tabela 1. Composição percentual e centesimal das rações basais crescimento I, crescimento II e terminação fornecidas durante o período experimental.

\begin{tabular}{lccc}
\hline Ingredientes (\%) & Crescimento I & Crescimento II & Terminação \\
\hline Quirera de arroz moída & 71,38 & 73,53 & 79,05 \\
Farelo de soja 46\% & 24,40 & 23,30 & 18,30 \\
Óleo vegetal & 0,60 & 0,40 & - \\
Sal & 0,40 & 0,40 & 0,50 \\
Calcário calcítico & 0,50 & 0,80 & 0,70 \\
Fosfato bicálcico & 1,70 & 1,20 & 1,20 \\
Dl-metionina & 0,13 & 0,03 & - \\
L-lisina 98\% & 0,34 & 0,09 & 0,06 \\
L-treonina & 0,11 & 0,03 & 0,02 \\
Colina 60\% & 0,24 & 0,02 & 0,01 \\
Suplemento vitamínico ${ }^{1}$ & 0,10 & 0,10 & 0,06 \\
Suplemento mineral ${ }^{2}$ & 0,10 & 0,10 & 0,10 \\
Total & 100 & 100 & 100 \\
\hline Valores Calculados $^{\text {Proténa Bruta (\%) }}$ & & & 15,019 \\
Cálcio (\%) & 17,985 & 16,993 & 0,752 \\
Fósforo disponível (\%) & 0,815 & 0,805 & 0,348 \\
EM (kcal/kg) & 0,455 & 0,359 & 3336 \\
Lisina total (\%) & 3352 & 3350 & 0,823 \\
Metionina total (\%) & 1,199 & 0,976 & 0,2629 \\
\hline
\end{tabular}

${ }^{1}$ Valores calculados por kg do produto: vit.A, 7.500.000 UI; vit.D3, $1.500 .000 \mathrm{UI}$; vit.E, 25.000mg; vit.K3, 1.000mg; vit.B1, 1.000mg; vit.B2, 5.000mg; vit.B6, 1.000mg; vit.B12, 14.000mcg; biotina, 250.000mcg; ác. Pantotênico, $14.000 \mathrm{mg}$; ácido fólico, 400.000mcg; ác. nicotínico, $18.000 \mathrm{mg}$. ${ }^{2}$ Magnésio, 666mg; enxofre, $85.864,110 \mathrm{mg}$; manganês, $40.000 \mathrm{mg}$; cobre, $15.000 \mathrm{mg}$; ferro, $80.000 \mathrm{mg}$; zinco, $99.867,810 \mathrm{mg}$; iodo, 300mg; selênio, 300mg. 
As variáveis de desempenho (ganho diário de peso, consumo diário de ração e conversão alimentar) foram calculadas a partir de pesagens semanais e da quantificação da sobra de ração nos comedouros.

Antecedendooabate, os animaisforamsubmetidos ao jejum alimentar de 17 horas, mantendo-se a dieta hídrica ad libitum. Os suínos foram transportados no início da manhã para um frigorífico localizado a $45 \mathrm{~km}$ da cidade de Londrina, sendo que o tempo do transporte foi de 1 hora. $\mathrm{O}$ abate dos animais foi realizado aos 156 dias de idade com peso médio de $115,89 \pm 7,48 \mathrm{Kg}$.

Para as análises das características de carcaça e da qualidade de carne, foi utilizado o delineamento inteiramente ao acaso, sendo cada animal considerado uma repetição.

$\mathrm{O}$ abate seguiu os procedimentos convencionais, com insensibilização elétrica e incisão da veia jugular. Após a escaldagem, evisceração e lavagem das carcaças, estas foram divididas ao meio longitudinalmente e pesadas para se obter o peso da carcaça quente (PCQ). Após 45 minutos do abate foi medido o $\mathrm{pH}$ ( $\mathrm{pH}$ inicial) no músculo Longissimus dorsi, na altura da última costela da meia carcaça esquerda, com auxílio do potenciômetro Sentron 1001. Na seqüênciaas carcaças foramacondicionadas em câmara fria à temperatura de $2 \pm 1^{\circ} \mathrm{C}$.

Após 24 horas de resfriamento, as carcaças foram pesadas, obtendo-se o peso da carcaça fria (PCF). $\mathrm{O}$ pH foi novamente medido para obtenção do pH final. Cada meia carcaça esquerda foi avaliada de acordo com as orientações da Associação Brasileira de Criadores de Suínos - ABCS (1973). Foram medidos o comprimento de carcaça (CC), a profundidade do músculo (PM) Longissimus dorsi e as espessuras de toucinho na primeira costela (ET1), na última costela (ET2) e na última vértebra lombar (ET3), sendo calculada a média destes três pontos (ET). O contorno do lombo foi desenhado em papel vegetal para o cáalculo da área do olho de lombo (AOL), realizada através do programa de informática Autocad 2000 (BRIDI; SILVA, 2006).

A medida da espessura de toucinho e da profundidade do lombo foi realizada na altura do ponto $\mathrm{P} 2$, localizado na região de inserção da última vértebra torácica com a primeira lombar a seis centímetros da linha média de corte da carcaça (BRIDI; SILVA, 2006). Com estes valores foi calculado o rendimento de carne na carcaça (RCC) e a quantidade de carne na carcaça (QCC), segundo as fórmulas propostas por Irgang (2004) apud Bridi e Silva (2006).

Após as análises de carcaça, estas foram seccionadas para a retirada do músculo Longissimus dorsi. Transportadas ao laboratório, as peças foram desossadas para a extração do lombo e a gordura adjacente do músculo foi retirada. No sentido caudal-cranial foram retiradas três amostras (bifes) do lombo de cada carcaça: a primeira para a análise de cor, marmoreio e perda de água por gotejamento; a segunda para a avaliação da perda de água no descongelamento e na cocção e para medir a força de cisalhamento (maciez); e a terceira para a análise sensorial. A segunda e a terceira amostras foram congeladas $\left(-4^{\circ} \mathrm{C}\right.$ em freezer comercial) para posteriores análises.

A avaliação da cor foi realizada com auxílio do aparelho colorímetro portátil Color - guide 45/0 D65/10 ${ }^{\circ}$ da marca BYK Gardner, que forneceu os valores de $\mathrm{L}^{*}$ (luminosidade), $\mathrm{a}^{*}$ (componente vermelho-verde) e $b^{*}$ (componente amarelo-azul) através do sistema de cor CIELAB.

O grau de marmorização foi realizado pelo método indireto utilizando-se padrões fotográficos (NATIONAL PORK PRODUCERS COUNCIL, 1991), atribuindo-se notas de 1 a 5 ( $1=$ traços de marmoreio; e 5 = marmoreio abundante).

A capacidade de retenção de água da carne foi avaliada por três metodologias: perda de água por gotejamento (BOCCARD et al., 1981), perda de água no descongelamento (diferença em porcentagem do peso da amostra congelada e descongelada em temperatura de $4^{\circ} \mathrm{C}$ por $24 \mathrm{~h}$ ) e perda de água 
na cocção (diferença em porcentagem do peso da amostra descongelada e assada em forno por 40 minutos a temperatura de $170^{\circ} \mathrm{C}$ ).

A avaliação de maciez foi realizada através da força de cisalhamento fornecida em $\mathrm{kg} / \mathrm{mm}^{2}$, em amostras de formato cilíndrico e previamente cozidas, por meio da lâmina HDP/BSW WarnerBratzler acoplada ao texturômetro Stable Mycro Systems TA - XT2i (BOUTON; HARRIS; SHORTHOUSE, 1971).

A análise sensorial foi realizada com o objetivo de avaliar o aroma e o sabor das amostras através do Teste de Ordenação (DUTCOSKY, 1996). As amostras foram assadas sem adição de tempero, por 50 minutos, em forno à temperatura de $180^{\circ} \mathrm{C}$. Foram utilizados 45 provadores não treinados que ordenaram as amostras em seqüência decrescente de sabor, ou seja, da mais saborosa para a menos saborosa.

Todos os dados de desempenho, carcaça e carne (com exceção da análise sensorial) foram submetidos à análise de variância e a comparação das médias ao teste de Tukey, utilizando-se o programa SAEG (UNIVERSIDADE FEDERAL DE VIÇOSA, 1997).

\section{Resultados e Discussão}

As médias das variáveis ganho diário de peso, consumo diário de ração e conversão alimentar para as fases de crescimento I, crescimentos I + crescimento II, e total (crescimentos I + crescimento II + terminação) e o peso vivo dos suínos ao final do período experimental encontram-se na Tabela 2.

Tabela 2. Efeito dos tratamentos experimentais sobre o ganho diário de peso (GDP), consumo diário de ração (CDR), conversão alimentar (CA) e peso final (PF) em suínos nas fases crescimento I (Fase I), crescimento I + crescimento II (Fase I+II) e período experimental total, crescimento I + crescimento II + terminação (Fase Total).

\begin{tabular}{|c|c|c|c|c|c|}
\hline \multirow[t]{2}{*}{ Parâmetros } & \multicolumn{5}{|c|}{ Tratamentos } \\
\hline & Controle & Prebióticos $0,2 \% *$ & $\begin{array}{l}\text { Apramicina } \\
15 \mathrm{ppm}\end{array}$ & $\begin{array}{l}\text { Apramicina } 15 \mathrm{ppm}+ \\
\text { prebióticos } 0,2 \%{ }^{*}\end{array}$ & $\begin{array}{l}\text { Coef. } \\
\text { Var. }(\%)\end{array}$ \\
\hline \multicolumn{6}{|l|}{ Fase I } \\
\hline GDP, kg & $0,844 \pm 0,05 \mathrm{a}$ & $0,871 \pm 0,05 \mathrm{a}$ & $0,873 \pm 0,08 \mathrm{a}$ & $0,837 \pm 0,04 \mathrm{a}$ & 7,15 \\
\hline CDR, kg & $1,93 \pm 0,16 \mathrm{a}$ & $1,83 \pm 0,15 \mathrm{a}$ & $1,95 \pm 0,22 \mathrm{a}$ & $2,02 \pm 0,07 \mathrm{a}$ & 8,75 \\
\hline $\mathrm{CA}$ & $2,28 \pm 0,13 \mathrm{ab}$ & $2,10 \pm 0,11 \mathrm{a}$ & $2,23 \pm 0,17 \mathrm{ab}$ & $2,42 \pm 0,17 \mathrm{~b}$ & 6,78 \\
\hline \multicolumn{6}{|l|}{ Fase I+II } \\
\hline GDP, kg & $0,916 \pm 0,02 \mathrm{a}$ & $0,966 \pm 0,03 \mathrm{a}$ & $0,968 \pm 0,03 \mathrm{a}$ & $0,887 \pm 0,04 \mathrm{a}$ & 12,94 \\
\hline $\mathrm{CDR}, \mathrm{kg}$ & $2,40 \pm 0,03 \mathrm{a}$ & $2,43 \pm 0,05 a$ & $2,45 \pm 0,02 \mathrm{a}$ & $2,43 \pm 0,02 \mathrm{a}$ & 6,72 \\
\hline $\mathrm{CA}$ & $2,64 \pm 0,09 \mathrm{a}$ & $2,54 \pm 0,09 \mathrm{a}$ & $2,56 \pm 0,07 \mathrm{a}$ & $2,79 \pm 0,15 \mathrm{a}$ & 8,62 \\
\hline \multicolumn{6}{|l|}{ Fase Total } \\
\hline GDP, $\mathrm{kg}$ & $0,955 \pm 0,07 \mathrm{a}$ & $1,007 \pm 0,05 \mathrm{a}$ & $1,012 \pm 0,07 \mathrm{a}$ & $0,980 \pm 0,09 \mathrm{a}$ & 6,40 \\
\hline $\mathrm{CDR}, \mathrm{kg}$ & $2,64 \pm 0,16 a$ & $2,77 \pm 0,21 \mathrm{a}$ & $2,78 \pm 0,17 \mathrm{a}$ & $2,69 \pm 0,24 a$ & 7,43 \\
\hline $\mathrm{CA}$ & $2,76 \pm 0,11 \mathrm{a}$ & $2,75 \pm 0,13 a$ & $2,75 \pm 0,09 \mathrm{a}$ & $2,74 \pm 0,08 \mathrm{a}$ & 4,04 \\
\hline $\mathrm{PF}, \mathrm{kg}$ & $113,84 \pm 4,29 \mathrm{a}$ & $118,98 \pm 5,40 \mathrm{a}$ & $118,39 \pm 6,00 \mathrm{a}$ & $117,02 \pm 8,31 \mathrm{a}$ & 4,64 \\
\hline
\end{tabular}

Médias seguidas de letras diferentes na mesma linha diferem $(\mathrm{P}<0,05)$ pelo teste de Tukey.

* (01\% mananoligossacarídeo $+0,1 \%$ frutoligossacarídeo $)$ 
Somente foi verificada diferença $(\mathrm{P}<0,05)$ para o parâmetro conversão alimentar, na fase de crescimento I, para os animais que receberam a dieta com prebióticos em relação ao tratamento com o apramicina + prebióticos. Para os outros períodos experimentais não houve diferença para nenhuma variável de desempenho analisada.

A melhor conversão alimentar na Fase I para o tratamento com prebióticos $(0,1 \%$ mananoligossacarídeo $+0,1 \%$ frutoligossacarídeo), emrelaçãoao grupotratado com 15 ppmdeapramicina + prebióticos $(0,1 \%$ mananoligossacarídeo $+0,1 \%$ frutoligossacarídeo), e a ausência de diferença em relação aos demais tratamentos, não permite indicar uma vantagem para o uso dos prebióticos na apresentação e concentração utilizadas, quer como um aditivo promotor isolado quer associado à apramicina. Todavia, Gebbink et al. (1999), trabalhando com leitões em fase de creche, sob condição de alto desafio sanitário, obtiveram melhor conversão alimentar quando usaram altos níveis de frutoligossacarídeo (5\%) em relação a um antibiótico tradicional $(0,05 \%$ de virginamicina). Os autores observaram que houve uma redução da população de E.coli e aumento da população de bifidobactérias no cólon distal dos leitões tratados com frutoligossacarídeos $(\mathrm{P}<0,05) \mathrm{em}$ relação ao tratamento com antibiótico e ao grupo controle, indicando que este prebiótico interferiu na modulação benéfica da microbiota, contribuindo para um ambiente intestinal mais favorável aos processos digestórios.

Para os parâmetros ganho diário de peso e consumo diário de ração na Fase I, a ausência de diferença entre os tratamentos se assemelha aos resultados observados por Ko, Kim e Han (2000), que avaliaram suínos em fase inicial de crescimento (primeiros 28 dias) alimentados com três tipos de ração, com $0,04 \%$ de clortetraciclina, com $0,1 \%$ de mananoligossacarídeo e isenta de promotores de crescimento. No entanto, os autores observaram que no período total do teste, correspondente à duração de 42 dias, os animais do tratamento controle apresentaram menor ganho diário de peso e menor consumo diário de ração em relação aos animais que receberam prebiótico.

Para a Fase I+ II e Fase total não foram verificadas diferenças entre os tratamentos sobre os parâmetros de desempenho.

Os resultados obtidos confirmam as observações de Houdijk et al. (1998) e Budiño (2004), que utilizando promotores alternativos, comparados com antimicrobianos promotores e com rações livres destes, indicaram que podem ocorrer variações nos resultados de desempenho em determinadas fases ou etapas experimentais. Porém, ao analisarem o trabalho em todo o período experimental não verificaram diferenças entre os tratamentos.

Neste sentido, Cardoso, Mestre e Pickard (2004), Rekiel, Wiecek e Dziuba (2005) e Campbell et al. (2006), trabalhando com diferentes aditivos promotores de crescimento, incluindo prebióticos e antibióticos, não encontraram diferenças em nenhuma das fases estudadas.

Campbell et al. (2006) não verificaram diferenças ( $\mathrm{P}>0,05)$ no desempenho de suínos em fase de terminação que receberam dietas suplementadas com uma fonte comercial de mananoligossacarídeos, acidificantes, ácido fumárico ou antibiótico mais óxido de zinco. Os autores explicam que a ausência de resultados positivos quando se avalia o uso de prebióticos como promotores de crescimento devese à baixa inclusão destes nas rações, à expressiva quantidade de oligossacarídeos presente nos cereais e na soja da dieta basal e ao bom estado de saúde e à idade dos animais. Contudo, os resultados obtidos divergem daqueles reportados por Davis et al. (2002), que observaram um aumento no ganho diário de peso de suínos em fases de crescimento e terminação que receberam mananoligossacarídeos e cobre em suas dietas, comparados com um grupo controle.

Os resultados das características de carcaça estão apresentados na Tabela 3 . 
Tabela 3. Efeito dos tratamentos experimentais sobre os parâmetros: peso de carcaça quente (PCQ), peso da carcaça fria (PCF), comprimento de carcaça $(\mathrm{CC})$, profundidade do músculo Longissimus dorsi (PM), espessura de toucinho (ET), rendimento de carcaça (RC), rendimento de carne na carcaça (RCC), quantidade de carne na carcaça (QCC) e área de olho de lombo (AOL).

\begin{tabular}{|c|c|c|c|c|c|}
\hline \multirow[t]{2}{*}{ Parâmetros } & \multicolumn{4}{|c|}{ Tratamentos } & \multirow{2}{*}{$\begin{array}{l}\text { Coeficiente de variação } \\
(\%)\end{array}$} \\
\hline & Controle & $\begin{array}{l}\text { Prebióticos } \\
0,2 \% \%^{*}\end{array}$ & $\begin{array}{l}\text { Apramicina } \\
15 \mathrm{ppm}\end{array}$ & $\begin{array}{c}\text { Apramicina } 15 \mathrm{ppm}+ \\
\text { prebióticos } 0,2 \%^{*}\end{array}$ & \\
\hline PCQ (kg) & $88,24 \pm 7,05 a$ & $90,77 \pm 5,87 a$ & $90,09 \pm 7,08 \mathrm{a}$ & $8 * 9,36 \pm 7,00 a$ & 7,09 \\
\hline PCF (kg) & $85,80 \pm 5,22 a$ & $88,97 \pm 5,73 a$ & $88,24 \pm 7,05 \mathrm{a}$ & $87,45 \pm 6,92 \mathrm{a}$ & 7,20 \\
\hline $\mathrm{CC}(\mathrm{cm})$ & $99,38 \pm 3,11 \mathrm{a}$ & $99,02 \pm 2,31 \mathrm{a}$ & $100,50 \pm 2,08 \mathrm{a}$ & $99,87 \pm 3,70 \mathrm{a}$ & 2,90 \\
\hline PM (mm) & $56,03 \pm 3,74 a$ & $57,89 \pm 5,81 a$ & $54,30 \pm 3,02 \mathrm{a}$ & $56,29 \pm 3,34 a$ & 7,10 \\
\hline $\mathrm{ET}(\mathrm{mm})$ & $30,13 \pm 2,96 a$ & $30,42 \pm 5,45 a$ & $31,44 \pm 4,12 \mathrm{a}$ & $31,34 \pm 3,05 a$ & 12,67 \\
\hline $\mathrm{AOL}(\mathrm{cm})$ & $34,77 \pm 3,29 b$ & $39,46 \pm 4,03 \mathrm{a}$ & $36,83 \pm 2,75 \mathrm{ab}$ & $36,20 \pm 1,80 \mathrm{ab}$ & 8,23 \\
\hline RC (\%) & $76,94 \pm 1,78 a$ & $77,32 \pm 1,65 a$ & $76,26 \pm 1,59 \mathrm{a}$ & $77,19 \pm 0,78 \mathrm{a}$ & 1,96 \\
\hline $\operatorname{RCC}(\%)$ & $53,30 \pm 3,34 a$ & $53,53 \pm 2,71 a$ & $52,98 \pm 2,27 \mathrm{a}$ & $53,54 \pm 2,00 \mathrm{a}$ & 4,95 \\
\hline QCC (kg) & $45,63 \pm 2,54 a$ & $47,52 \pm 2,15 a$ & $46,68 \pm 3,28 \mathrm{a}$ & $46,73 \pm 2,68 \mathrm{a}$ & 5,87 \\
\hline
\end{tabular}

Médias seguidas de letras diferentes na mesma linha diferem $(\mathrm{P}<0,05)$ pelo teste de Tukey.

* (01\% mananoligossacarídeo $+0,1 \%$ frutoligossacarídeo $)$

Pode-se observar que somente para a área de olho de lombo foi identificada diferença $(\mathrm{P}<0,05)$ entre os tratamentos prebióticos $(0,2 \%)$ e controle, sendo verificada uma área $13,48 \%$ maior para o grupo tratado com o promotor alternativo. Este resultado pode ser explicado pelos prebióticos (mananoligossacarídeos + frutoligossacarídesos) terem favorecido a microbiota intestinal, possibilitando, assim, uma melhor utilização de proteínas para o desenvolvimento muscular.

Os resultados obtidos, excetuando a vantagem na área do olho de lombo, foram semelhantes aos observados por Cardoso, Mestre e Pickard (2004) e Rekiel, Wiecek e Dziuba (2005), que não encontraram diferenças sobre os parâmetros de carcaça de suínos submetidos a tratamentos com mananoligossacarídeos e antibióticos nas dietas. Bae, Ko e Kim (1999) também não verificaram diferenças nas características de carcaça de suínos tratados, a partir dos $68 \mathrm{~kg}$ de peso vivo até o abate, com dietas suplementadas com quatro aditivos distintos: $0,1 \%$ de mananoligossacarídeos, extrato de yucca, $0,1 \%$ de beta-glucanos e clortetraciclina.

Os parâmetros avaliados relacionados à qualidade de carne estão apresentados na Tabela 4.

Não foram encontradas diferenças entre os parâmetros para as distintas dietas experimentais $(\mathrm{P}<0,05)$, indicando ausência de efeitos sobre as características qualitativas da carne.

A análise sensorial não apresentou diferença entre os tratamentos quanto ao aroma e sabor, já que a maior diferença crítica encontrada entre os totais de ordenação ao nível de 5\% de significância foi de 13 pontos. Segundo a tabela de Newell e Mac Farlane, este valor deveria ser de no mínimo 32 pontos para resultar diferença significativa. 
Tabela 4. Efeito dos tratamentos experimentais sobre os parâmetros: porcentagem de perda de água por gotejamento (PAG), perda de água no descongelamento (PAD), perda de água na cocção (PAC), valores de cor (L*, a* e b*), pH inicial (pHi), pH final (pHf), mamoreio (MAR) e força de cisalhamento (FC) nas amostras do músculo Longissimus dorsi.

Parâmetros

Tratamentos

Coeficiente de variação

$(\%)$

\begin{tabular}{|c|c|c|c|c|c|}
\hline & Controle & $\begin{array}{l}\text { Prebióticos } \\
0,2 \% *\end{array}$ & $\begin{array}{l}\text { Apramicina } \\
15 \mathrm{ppm}\end{array}$ & $\begin{array}{c}\text { Apramicina } 15 \mathrm{ppm}+ \\
\text { prebióticos } 0,2 \% *\end{array}$ & \\
\hline$\overline{\mathrm{PAG}(\%)}$ & $3,99 \pm 1,11$ & $3,61 \pm 0,90$ & $3,57 \pm 0,47$ & $3,71 \pm 075$ & 22,07 \\
\hline $\operatorname{PAD}(\%)$ & $7,26 \pm 2,13$ & $7,45 \pm 0,50$ & $6,31 \pm 2,77$ & $7,75 \pm 1,64$ & 28,35 \\
\hline PAC(\%) & $28,62 \pm 5,20$ & $27,85 \pm 4,28$ & $29,60 \pm 4,78$ & $27,93 \pm 3,91$ & 16,14 \\
\hline $\mathrm{L}^{* 1}$ & $51,91 \pm 2,19$ & $53,46 \pm 2,85$ & $52,55 \pm 2,41$ & $51,97 \pm 2,21$ & 4,58 \\
\hline$a^{* 2}$ & $0,31 \pm 0,67$ & $0,77 \pm 1,32$ & $0,28 \pm 1,32$ & $0,47 \pm 0,54$ & 232,37 \\
\hline$a^{* 3}$ & $7,72 \pm 0,99$ & $8,42 \pm 1,23$ & $7,93 \pm 1,01$ & $8,30 \pm 0,66$ & 12,17 \\
\hline $\mathrm{pHi}$ & $6,08 \pm 0 \quad 0,33$ & $6,04 \pm 0,21$ & $5,90 \pm 0,27$ & $6,05 \pm 0,31$ & 4,78 \\
\hline pHf & $5,38 \pm 0,06$ & $5,35 \pm 0,03$ & $5,36 \pm 0,07$ & $5,41 \pm 0,09$ & 1,24 \\
\hline MAR & $2,04 \pm 0,41$ & $1,94 \pm 5,99$ & $1,77 \pm 0,56$ & $1,85 \pm 0,34$ & 26,54 \\
\hline $\mathrm{FC}(\mathrm{kgf})$ & $5,74 \pm 1,40$ & $5,75 \pm 0,87$ & $6,47 \pm 0,96$ & $6,26 \pm 1,09$ & 18,44 \\
\hline
\end{tabular}

${ }^{1}$ luminosidade; ${ }^{2}$ componente vermelho-verde; ${ }^{3}$ componente amarelo-azul

* $(01 \%$ mananoligossacarídeo $+0,1 \%$ frutoligossacarídeo $)$

\section{Conclusões}

Nas condições em que foi realizado o presente estudo, pode-se concluir que o uso dos prebióticos mananoligossacarídeo + frutoligossacarídeo, associados ou não à apramicina, determinou resultados semelhantes para as características de desempenho, carcaça e carne, permitindo sua adoção nas fases avaliadas.

\section{Referências}

ASSOCIAÇÃO BRASILEIRA DE CRIADORES DE SUÍNOS - ABCS. Método brasileiro de classificação de carcaças. 2. ed. Rio Grande do Sul: ABCS, 1973.

BAE, K. H.; KO, T. G.; KIM, J. H. Use of metabolically active substances to substitute for antibiotics in finishing pigs. Korean Journal of Animal Science, Suwon, v. 41, n. 1, p. 23-30, 1999.

BELLAVER, C. O uso de microingredientes (aditivos) na formulação de dietas para suínos e suas implicações na produção e na segurança alimentar. In: CONGRESSO MERCOSUL DE PRODUÇÃO SUÍNA, 1., Buenos Aires, 2000. Anais... Buenos Aires: FCV/UBA, FAV/ UNRC, EMBRAPA, 2000. p. 93-108.
BOCCARD， R.; BUCHTER, L.; CASSELS, E.; COSENTINO, E.; DRANSFIELD, E.; HOOD, D.; JOSEPH, R.; MAC DOUGALL, D.; RHODES, D.; SCHON, I.; TINBERGEN, B. J. TOURAILEE. C. Proceedings for measuring meat quality characteristics in beef production experiments. Livestock Production Science, Amsterdam, v. 8, n. 3, p. 385-397, 1981.

BOUTON, P. E.; HARRIS, P. V.; SHORTHOSE, W. R. Effect of ultimate $\mathrm{pH}$ upon the water-holding capacity and tenderness of mutton. Journal of Food Science, Champaign, v. 36, n. 3, p. 435-439, 1971.

BRIDI, A. M.; SILVA, C. A. Métodos de avaliação da carcaça e da carne suína. Londrina: Midiograf, 2006.

BUDIÑO, F. E. L. Probiótico elou prebiótico na dieta de leitões recém desmamados. 2004. Tese. (Doutorado em Zootecnia) - Faculdade de Ciências Agrárias e Veterinárias, Universidade Estadual Paulista, Jaboticabal.

CAMPBELL, A. J.; GARDINER, G. E.; LEONARD, F. C.; LYNCH, P. B.; SANTOS, C.; ROSS, R. P.; LAWLOR, $\mathrm{P}$. The effect of dietary supplementation of finishing pigs with organic acids or mannan-oligosaccharide on the coliform, Lactobacillus and Bifidobacterium flora of the intestinal contents and faeces. The Pig Journal, Malmesbury, v. 57, p. 90-104, 2006. 
CARDOSO, A. M. S.; MESTRE, R. B.; PICKARD, J. A. Grower-finishers fed Bio-Mos ${ }^{\circledR}$ achieve performance levels comparable to those achieved with an antibiotic growth promoter. In: INTERNATIONAL ANNUAL FEED INDUSTRY SYMPOSIUM, 20., 2004, Lexington. Proceedings... Lexington: Alltech, 2004. p. 52.

CLOSE, W. H. Producing pigs without antibiotic growth promoters. Advances in Pork Production, Edmonton, v. 11, p. 47-55, 2000.

CUMMINGS, J. H.; MACFARLANE, G. T. Gastrointestinal effects of prebiotics. British Journal of Nutrition, Cambridge, v. 87, Suppl. 2, p. S145-151, 2002.

CUNHA JÚNIOR, A.; SCHEUERMANN, G. N. Perspectivas para a utilização de produtos de origem vegetal como aditivos alternativos na alimentação de aves. 2005. Disponível em: <http://www.engormix. com/perspectivas_a_utilizacao_produtos_p_artigos_16 AVG.htm> Acesso em: 24 out. 2006.

DAVIS, M. E.; MAXWELL, C. V.; BROWN, D. C.; RODAS, B. Z.; JOHNSON, Z. B.; KEGLEY, E. B.; HELLWIG, D. H.; DVORAK, K. A. Effect of dietary mannan oligosaccharides and (or) pharmacological additions of copper sulfate on growth performance and immunocompetence of weaning and growing/finishing pigs. Journal of Animal Science, Champaign, v. 80, n. 11, p. 2887-2894, 2002.

DUTCOSKY, S. D. Análise sensorial dos alimentos. 2. ed. Curitiba: Universitária Champagnat, 1996.

FLICKINGER, E. A.; FAHEY JÚNIOR, G. C. Pet food and feed applications of inulin, oligofructose and other oligosaccharides. British Journal of Nutrition, Cambridge, v. 87, Suppl. 2, p. S297-S300, 2002.

GEBBINK, G. A. R.; SUTTON, A. L.; RICHERT, B. T.; PATTERSON, J. A.; KELY, D. T.; VERSTEGEN, M. W. A.; BOSCH, M.; COBB, M.; KENDALL, D. C.; DECAMP, S.; BOWERS, K. Effects of addition of fructooligosaccharide (FOS) and sugar beet pulp to weanling pig diets on performance, microflora and intestinal health. 1999. Disponível em: <http://www. ansc.purdue.edu/swine/swineday/sday99/psd09-1999. html >. Acesso em: 08 nov. 2006.
GÓMEZ, M. S. C. Development of gut microbiota in the pig: modulation of bacterial communities by different feeding strategies. 2006. Tese. (Doutorado em Produção Animal) - Universitat Autônoma de Barcelona, Barcelona.

HOUDIJK, J. G. M.; BOSCH, M. W.; VERSTEGEN, H. J.; BERENTAS, H. J. Effects of dietary oligosaccharides on the growth performance and faecal characteristics of young growing pigs. Animal Feed Science and Technology, Amsterdam, v. 71, n. 1, p. 35-48, 1998.

KO, T. G.; KIM, J. D.; HAN, Y. K. Study for the development of antibiotics-free diet for growing pigs. Korean Journal of Animal Science, Suwon, v. 42, n. 1, p. 45-54, 2000.

MENTEN, J. F. M. Aditivos alternativos na nutrição de aves: probióticos e prebióticos. In: REUNIÃO ANUAL DA SOCIEDADE BRASILEIRA DE ZOOTECNIA, 38., 2001, Piracicaba. Anais... Piracicaba: Sociedade Brasileira de Zootecnia, 2001. CD-ROM.

NATIONAL PORK PRODUCERS COUNCIL. Procedures to evaluate market. 3. ed. Des Moines: National Pork Producers Council, 1991.

NATIONAL RESEARCH COUNCIL-NRC. Nutritional requirements of swine. 10. ed. Washington: NRC, 1998.

PATTERSON, J. A. Prebiotic feed additives: rational and use in pigs. Advances in Pork Production, Edmonton, v. 16, p. 149-159, 2005.

REKIEL, A.; WIECEK, J.; DZIUBA, M. Effect of feed additives on the results of fattening and selected slaughter and quality traits of pork meat of pigs with different genotypes. Czech Journal of Animal Science, Praha, v. 50, n. 12, p. 561-567, 2005.

SILVA, L. P.; NÖRNBERG, J. L. Prebióticos na nutrição de não ruminantes. Ciência Rural, Santa Maria, v. 33, n. 2, p. 983-990, 2003.

UNIVERSIDADE FEDERAL DE VIÇOSA - UFV. SAEG - Sistema de análises estatísticas e genéticas. Versão 7.1. Viçosa: Ed. da UFV, 1997. 
